\title{
Quantitative Evaluation of Coal Structures with the Aid of Geophysical Logging Data
}

\author{
Teng Juan, Liu Dameng, Yao Yanbin, Cai Yidong \\ Coal Reservoir Laboratory of National CBM Engineering Center, School of \\ Energy Resources, China University of Geosciences, Beijing 100083, China \\ tengjuancugb@outlook.com
}

\begin{abstract}
Coal structure not only is a significant physical parameter of the coal reservoirs, but also has an effect on the coalbed methane (CBM) productivity during coal mining. In this paper, the clustering method is used to evaluate the coal structures quantitatively. For better application on the identification process of the coal structures, the clustering method is modified twice by ascertaining initial clustering centers and calibrating Euclidean distances, respectively. The quantitative method was applied to evaluate coal structures in 16 CBM wells in the Zhengzhuang field, Southern Qinshui Basin, North China. Results show that coal structures by the twice modified clustering method has good accordance with that by the coring samples. Therefore, coal structure identification using clustering method with the aid of geophysical logging data is feasible in the study area. The thickness proportions of coal structures have positive/ negative relationships with the corresponding average logging data. The multiple linear regression method was employed to predict the thickness proportions of coal structures. The predicted results show that prediction models of thickness proportions of coal structures are feasible to predict the distribution of coal structures fast in spite of the limited errors.
\end{abstract}

Keywords: coal structures, geophysical logging data, quantitative evaluation, modified K-Means method, thickness proportion models

\section{Introduction}

Coal structure is an important physical parameter of coal reservoir for its effect on the pore and fracture system and permeability of the coals [1-3]. With the increasing degree of coal deformation, the coal textures can be classified into the undeformed, cataclastic, grated and mylonitized coals $[4,5]$. Tectonically deformed coals with various structural characteristics and types are formed under different stress - strain conditions. The effect of structural deformation on main pores and fractures of coal seam is a shift from dominated transitional pores and micropores to mesopores, macropores and fractures $[4,5]$ with the increasing degree of coal deformation. The lithotypes, structures and endogenous fractures of the undeformed coal are well preserved, with mainly micropores and mesopores, low porosity and permeability and medium adsorption capacities. The main deformation characteristics of cataclastic coal are induced fractures, high porosity and permeability and low adsorption capacities. Tectonic deformation is produced in grated coal, which suffers shear failure, with granules partially and relatively low permeability $[6,7]$.

Previous studies have indicated that geophysical logging technology is an indicator of changes in the properties of coals using electrical, magnetic, nuclear and acoustic methods [8-10]. It has been shown that geophysical logging data can be used to identify coal structures [3, 11-12]. Fu et al. [1-3] classified the coals in Huainan and Huaibei coal mines in China into the original - textured/ruptured, grated, and the mylonitic coals with a vertical scale of $0.5 \mathrm{~m}$. Chen et al. [13] divided the coals in Hancheng field, Ordos Basin, North China, into three types of blocky, blocky-powdered and powdered coals with the aid of logging curves. However, previous coal structure identification using the well logs is based on qualitative description and 
analysis of the amplitude changes and morphological characteristics of geophysical logging curves. Thus the results are closely related to experience of the interpreters, which can hardly meet the demand of scientific research.

In this paper, the coal structures in the Southern Qinshui Basin, North China is taken as an example for the quantitative evaluation. The coal structures only include the undeformed, cataclastic and grated coals, without the mylonitized coals for relatively simple structure in the study area [14]. For fast and accurate identification of coal structures with the aid of digital logging data, an advanced clustering method for identification of coal structures with a scale of $0.1 \mathrm{~m}$ is proposed for the first time. At the same time, the proposed method will be verified by coal coring samples. Thickness proportion of grated coal is regarded as a significant parameter to evaluate high risk zone of gas outburst. Multiple linear regression method of logging data and thickness proportion of grated coal is utilized to establish thickness proportion prediction models for faster prediction of high risk zone of gas outburst.

\section{The Proposed Method}

\subsection{Well Logging Data}

Geophysical logging techniques provide a large amount of logging data from various coal mines and are often accessible to support fundamental research related to evaluation of coal reservoir properties. According to extant field logging data and changes of lithology, interval transit time, caliper, electricity and radioactivity from different coal structures, five log types of density, acoustic time, caliper, deep resistivity and natural gamma are used to characterize coal structures in this paper.

Density logging curve can directly be related to coal structures for more pores and fractures produced filled with formation water and coalbed methane in cataclastic coal and grated coal resulting in low density value $[3,14]$. Propagation velocity of acoustic wave in coal is faster than in gas and formation water. Thus, interval transit time from acoustic time logging is increasing with increasing volume proportion pores and fractures [7]. Acoustic time logging curves show high abnormal amplitude with the destruction of coal seam. Based on the strength of rock near borehole, the degree of hole enlargement is described by caliper logging. Mudstone, sandstone and limestone with greater strength less likely expand than coal seam [15] The higher amplitudes the caliper logging shows, the more serious the hole enlargement would be. Thus, caliper logging is first applied on the classification of coal structures. Deep resistivity can reflect the resistivity changes in neighboring borehole delicately. The resistivity of bituminous coal is much lower than coalbed methane [1-3]. Broken coal with more pores and fractures can absorb and preserve more gas, thus deep resistivity logging curve presents abnormally high amplitudes. Natural gamma logging data are used to quantify radioactive elements content in the coal seam. The more radioactive elements exist in coal seam, the higher value of natural gamma logging curves will show [15]. More induced pores and fractures are produced when coal seam suffers tectonic deformation, which results in less radioactive elements in per unit of coal and weaker strength of gamma ray. The natural gamma logs present decreasing trend with the destruction of coal seam. Therefore, with the increasing degree of coal deformation, the density and natural gamma logs show a decreasing trend, while the acoustic time, caliper and deep resistivity logs have an increasing trend.

For statistical analysis, logging data are normalized to eliminate errors from apparatus and differences in magnitude of logging data [3].

$$
X^{\prime}=\frac{X-X_{\min }}{X_{\text {max }}-X_{\min }}
$$

where, $X, X^{\prime}, X_{\max }$ and $X_{\min }$ represent any log variables, normalized data of $\mathrm{X}$, the maximum and the minimum values of corresponding parameters in the same borehole. 


\subsection{Methodology}

In this paper the clustering method is modified for better application on the coal structure identification using digital logging data. The K-Means method from the clustering method is selected for the algorithm of logging data. The idea of K-Means is to found $\mathrm{K}$ cluster centers in the data to make the sum of the Euclidian distance between every data point xi and its related nearest center to be minimal $[16,17]$, so the data will be classified into different types $[18,19]$.

The classic K-Means method is modified twice in this study. According to the most obvious abnormal amplitudes of log curves, the initial clustering centers (ICCs) are ascertained, which is considered as the first modification of the K-Means method. The Euclidean distances are used to characterize the similarity between a monolayer with a thickness of $0.1 \mathrm{~m}$ and three ICCs. The shorter Euclidean distances present greater similarity between monolayer and ICCs. The Euclidean distance is expressed as:

$$
d_{i}=\sqrt{\sum_{k=1}^{5}\left(x^{\prime}{ }_{k}-c_{i}\right)^{2}}
$$

where, $d_{i}$ represents the Euclidean distance between a monolayer and three ICCs; $x_{k}$ represents the normalized logging data; ck represents the ICCs; $i$ represents three types of coal structures $(i=1,2,3$ are the undeformed, cataclastic and grated coals, respectively); $k$ represents the No. of five logging curves $(k=1,2, \ldots, 5$ are density, acoustic time, caliper, natural gamma and deep resistivity logs, respectively).

The minimum distance of each monolayer $(D)$ is computed. The monolayer is classified into the undeformed coal when $i=1$, the cataclastic coal when $i=2$ and the grated coal when $i=3$. According to this step all the layers of coal seam are classified into three types of coal structures completely.

Changes in density, acoustics, hole enlargement situation, radioactive substance content and resistivity reflect the coal structures in different degrees. Therefore, there is a need to calculate the correlation degrees between each geophysical technique and coal structures to calibrate Euclidean distances for improving accuracy of clustering method. The grey correlation method is proposed to quantify the degrees.

First, the evaluation column of coal structures is defines as:

$$
X_{0}=\left\{X_{o}(1), X_{o}(2), \ldots, X_{o}(k), \ldots, X_{o}(n)\right\}
$$

To distinguish three types of coal structures, the normalized data of coal structures (undeformed coal, cataclastic coal and grated coal) are defined as 0, 0.5 and 1, respectively.

Second, the evaluation column of logging data are defines as:

$$
X_{i}=\left\{X_{i}(1), X_{i}(2), \ldots, X(k), \ldots, X_{i}(n)\right\}
$$

where, $n$ is the No. of monolayer; $k$ is the any No. of monolayer $(k=1,2, \ldots, n) ; i$ is the No. of five logging curves $(i=1,2, \ldots, 5)$.

According to the basic principle of grey correlation method, the grey correlation degree $\left(P_{i}\right)$ between any logging curve and coal structures is calculated:

$$
P_{i}=\frac{1}{n} \sum_{k=1}^{n} \frac{\min _{i} \min _{k}\left|X_{0}{ }^{\prime}(k)-X_{i}{ }^{\prime}(k)\right|+\rho \max _{i} \max _{k}\left|X_{0}{ }^{\prime}(k)-X_{i}{ }^{\prime}(k)\right|}{\left|X_{0}{ }^{\prime}(k)-X_{i}{ }^{\prime}(k)\right|+\rho \max _{i} \max _{k}\left|X_{0}{ }^{\prime}(k)-X_{i}{ }^{\prime}(k)\right|}
$$

grey resolution ratio, $\rho=0.5$ [20].

where, $\rho$ is

Thus, the K-Means method is modified in the second time, which is regarded as the second modification of the K-Means method. The calibrated Euclidean distance $\left(d_{i}{ }^{\prime}\right)$ is expressed as:

$$
d_{i}^{\prime}=\sqrt{\sum_{\mathrm{k}=1}^{5}\left(P_{i} *\left(x^{\prime}{ }_{k}-\mathrm{c}_{i}\right)\right)^{2}}
$$

Thus, the coal texture identification model is established. In this study, this model was applied on 15 wells to evaluate coal structures. The relationships between the thickness 
proportions of coal structures and the logging data were studied using multiple linear regression models. The flow chart in Fig. 1 graphically presents the details of the identification methodology of coal structures and application followed for this approach. The details of the techniques will be given in the next sections in this paper.

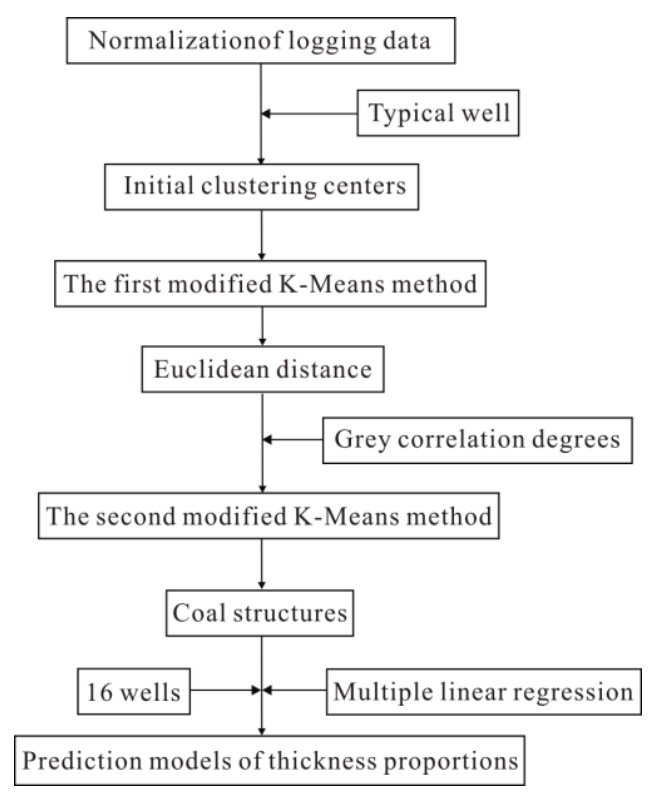

\section{Figure 1. The Flow Chart Representation of the Quantitative Identification of the Coal Structures}

\section{Results and Discussion}

\subsection{Calculated Results of Typical Well}

The well of ZS35 is chosen as the typical well for a great thickness of the undeformed, cataclastic and grated coals. The classification results of first-modified K-Means method using Euclidean distance are shown in Fig. 2a. Normalized logging data of three kinds of ICCs with the most obvious abnormal amplitudes and calculation results of gray correlation degrees between logging data and coal structures are shown in Table 1 . The density logging has the maximum grey correlation degree $(\mathrm{GCD})$ of 0.6760 , while the natural gamma logging curve has the minimum GCD of 0.5641 . Caliper logging has a good correlation with coal structures with grey correlation degree of 0.6488 , which proves that caliper logging can be used as a geophysical technique to identify coal structures quantitatively.

Results of coal structures from the second modified K-Means method and the macroscopic description of 8 coring samples are shown in Fig. $2 a$ and $2 b$, respectively. From the top to the bottom, the coals are the undeformed, cataclastic, undeformed, grated, grated, cataclastic, cataclastic and cataclastic coals, respectively.

Table 1. Normalized Logging Data of ICCs of Coal Textures and GCDs between the Logs and Coal Structures

\begin{tabular}{ccccc}
\hline \multirow{2}{*}{ Logging data } & \multicolumn{3}{c}{ ICCs } & \multirow{2}{*}{ GCDs } \\
\cline { 2 - 4 } & Undeformed coal & Cataclastic coal & Grated coal & \\
\hline Density & 0.2891 & 0.1314 & 0.1119 & 0.6760 \\
Acoustic time & 0.5835 & 0.8091 & 0.8172 & 0.6189 \\
Caliper & 0.0585 & 0.2268 & 0.1998 & 0.6488 \\
Deep resistivity & 0.5118 & 0.2444 & 0.8818 & 0.6154 \\
Natural gamma & 0.3270 & 0.1603 & 0.0643 & 0.5641 \\
\hline
\end{tabular}


Comparison of identification results with the coring samples shows that layered coal structures results of the second-modified K-Means method have good accordance with the coring samples. There exists uncertainty in the second-modified K-Means method. Errors from the identification method are derived from influences of the vertical heterogeneity and solution of the geophysical logs. However, the errors are controlled within limits. Therefore, the modified clustering method is feasible for the coal structure identification.
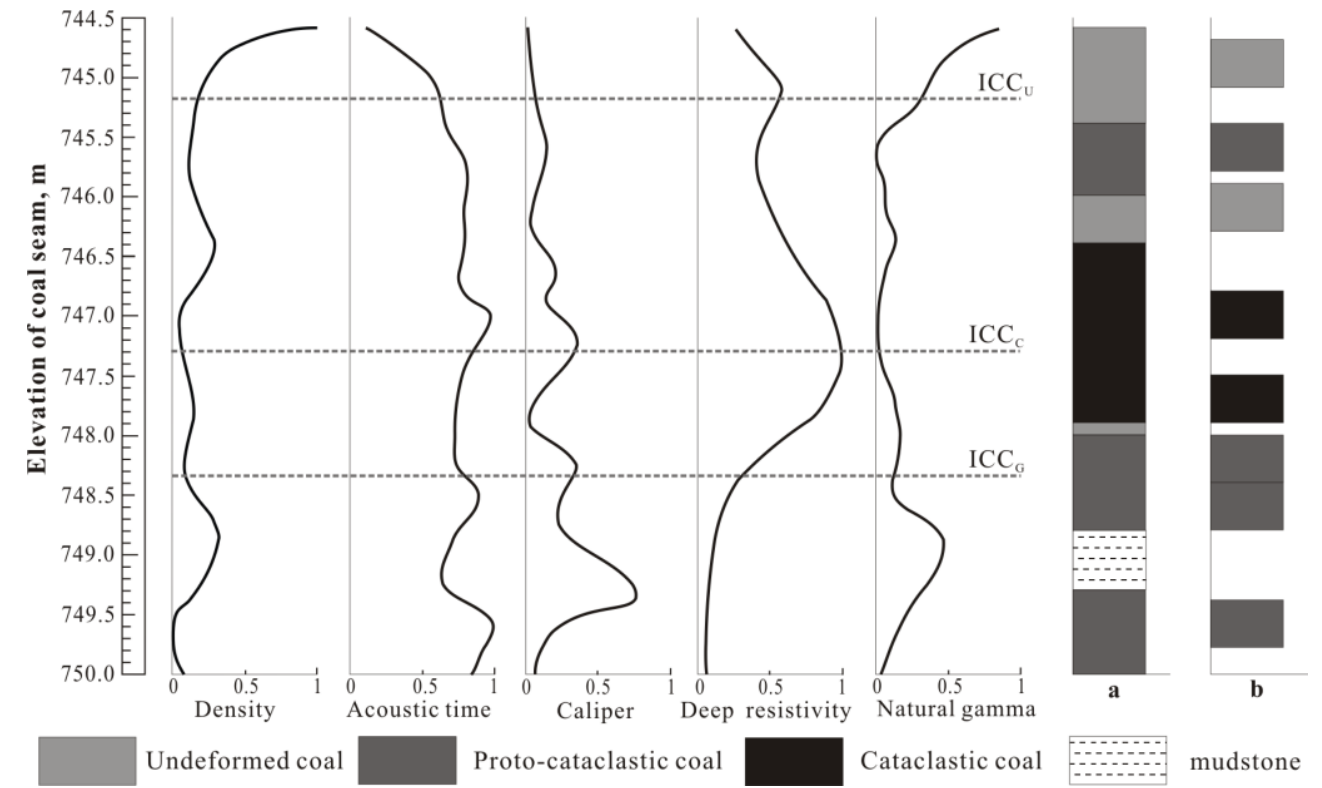

Figure 2. Normalized Logging Curves and Ascertained ICCs of the Well ZS35 and Coal Structure Identification Results from the Second - modified (a) K-Means Method and 8 Coring Samples (b) in Zhengzhuang Field

For these neighboring coals of the Well ZS35 in Zhengzhuang field, there exists a similarity in coal forming substances, sedimentary environment, coal rank and mineral matter content. Thus, it is possible that the quantitative method for coal structure identification using digital logging data can be applied on the whole research area. The average logging data of each coal structure of the Well ZS35 are selected as the clustering centers. Table 2 gives the clustering centers and GCDs used for identification of coal structures in the rest of 15 wells using the second-modified K-Means method calculated by Eq. (7).

Table 2. Geophysical Logging Data of Identification Results of Coal Structures of the Well ZS35

\begin{tabular}{cccccc}
\hline Clustering centers & Density & $\begin{array}{c}\text { Acoustic } \\
\text { time }\end{array}$ & Caliper & Deep resistivity & $\begin{array}{c}\text { Natural } \\
\text { gamma }\end{array}$ \\
\hline Undeformed coal & 0.2891 & 0.5835 & 0.0585 & 0.5118 & 0.3270 \\
Cataclastic coal & 0.1314 & 0.8091 & 0.2268 & 0.2444 & 0.1603 \\
Grated coal & 0.1119 & 0.8172 & 0.1998 & 0.8818 & 0.0643 \\
\hline
\end{tabular}

\subsection{Thickness Proportion Prediction Models}

The relationships between the thickness proportions and the average logging data of coal structures in 16 wells are studied. Fig. 3 shows that the thickness proportions decrease or increase with the increasing logging data. Most of the data points in Fig. 3 are independent in a narrow stripe, and a few points are in overlapping region. and grated coal have higher acoustic time value (Fig. 3b). Cross plot of thickness proportion- caliper manifests points of the undeformed coal decrease with lower caliper of 0.05-0.4. Data points in Fig. 3c is extensive, 
especially in the cataclastic and grated coal, because hole enlargement is easier taken place in the grated coal when suffers structural damage. Cross plot of deep resistivity - thickness proportion shows points of three coal structures are distributed in independent areas (Fig. 3d). Points of the undeformed coal have an increasing trend with lower resistivity of $0.01-0.4$, the cataclastic coal a sharp decreasing trend with lower resistivity of 0.1-0.35 and the grated coal a sharp decreasing trend with higher resistivity of 0.75-0.9 (Fig. 3d). Cross plot of natural gamma - thickness proportion presents points of three coal structures are spread in independent areas (Fig. 3e). Points of the undeformed coal have a decreasing trend with higher natural gamma value of 0.4-0.9, the cataclastic coal a decreasing trend with mediate natural gamma value of 0.2-0.5 and grated coal an increasing trend with lower natural gamma value of 0.02-0.2 (Fig. $3 \mathrm{e})$.
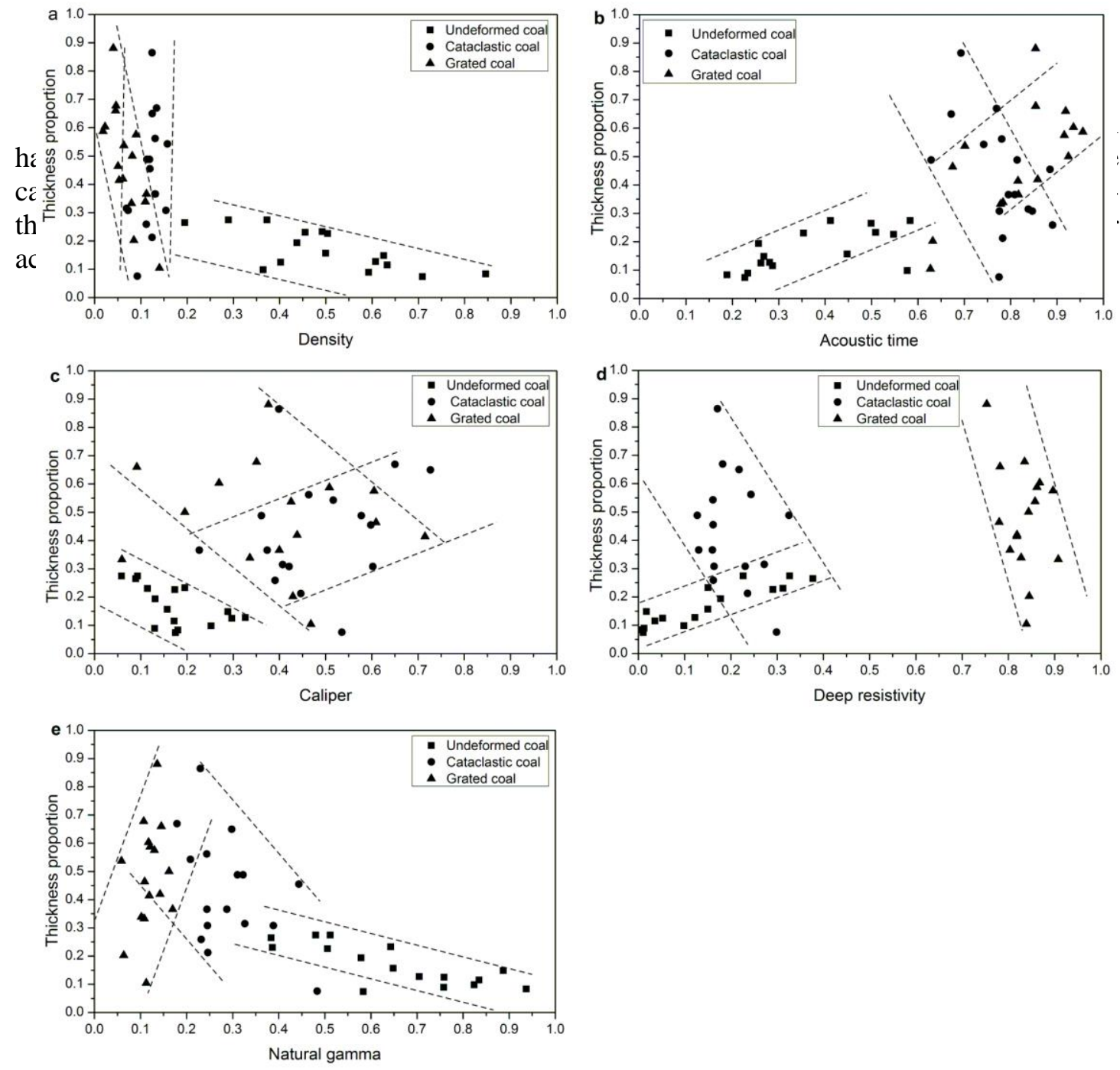

Figure 3. Crossplots of the Relationships between Thickness Proportions and Logging Data (a, density; b, Acoustic Time; c, Caliper; d, Deep Resistivity and e, Natural Gamma) of Coal Structures in Zhengzhuang field. Cataclastic

Based on the corresponding relationships between thickness proportion and average logging data of each coal structure, the multiple linear regression method is proposed to build the prediction models of thickness proportions. Modeling calculation is done with a regression model in the software "SPSS Statistics 20". Three prediction models of coal structures were checked with F-test in terms of significance and accuracy (Table 3). 
Table 3. The Prediction Models of Thickness Proportions of Coal Structures using the Multiple Linear Regression Method

\begin{tabular}{|c|c|c|c|c|c|}
\hline Types & Thickness Proportions & $\mathrm{R}$ & $\mathrm{R}^{2}$ & $\mathrm{~F}$ & Sig \\
\hline Undeformed coal & $\begin{array}{c}\mathrm{P}_{\mathrm{u}}=-0.146 * \rho+0.283 * \Delta \mathrm{t}-0.071 * \mathrm{r}+ \\
\quad 0.163 * \mathrm{R}+0.028 * \gamma+0.108\end{array}$ & 0.88 & 0.77 & 13.77 & 0.00 \\
\hline Cataclastic coal & $\begin{aligned} \mathrm{P}_{\mathrm{c}}= & 0.460 * \rho-0.049 * \triangle \mathrm{t}+0.337 * \mathrm{r}+ \\
& 0.377 * \mathrm{R}-0.883 * \gamma+0.527\end{aligned}$ & 0.61 & 0.37 & 2.47 & 0.03 \\
\hline Grated coal & $\begin{aligned} \mathrm{P}_{\mathrm{g}}= & -1.284 * \rho+0.386 * \triangle \mathrm{t}+0.185 * \mathrm{r}+ \\
& 1.136 * \mathrm{R}+0.163 * \gamma-0.964\end{aligned}$ & 0.67 & 0.45 & 3.48 & 0.02 \\
\hline
\end{tabular}

As extensive data range (Fig. 3) imposes a certain mount errors in the prediction of thickness proportion using multiple linear regression method. Errors (E) are expressed as:

$$
E=\frac{\left|P_{c}-P_{p}\right|}{P} \times 100 \%
$$

where, $P_{c}$ and $P_{p}$ are the thickness proportions from clustering method and prediction models, respectively. The results of errors analysis of prediction models show that errors of three coal structures are limited within $40 \%$ with an average of about $16 \%$ (Table 4). Therefore, the prediction models of thickness proportions of coal structures are feasible.

Table 4. Errors Analysis of the Prediction Models of Thickness Proportions

\begin{tabular}{cccccccccc}
\hline & \multicolumn{3}{c}{ Undeformed coal } & \multicolumn{3}{c}{ Cataclastic coal } & \multicolumn{3}{c}{ Grated coal } \\
\cline { 2 - 10 } Well No. & $\mathrm{P}_{\mathrm{c}}$ & $\mathrm{P}_{\mathrm{p}}$ & $\mathrm{E}$ & $\mathrm{P}_{\mathrm{c}}$ & $\mathrm{P}_{\mathrm{p}}$ & $\mathrm{E}$ & $\mathrm{P}_{\mathrm{c}}$ & $\mathrm{P}_{\mathrm{p}}$ & $\mathrm{E}$ \\
\hline ZS30 & 0.27 & 0.29 & 8.32 & 0.56 & 0.58 & 4.07 & 0.18 & 0.22 & 24.97 \\
ZS 31 & 0.27 & 0.21 & 21.99 & 0.42 & 0.51 & 21.40 & 0.31 & 0.32 & 5.40 \\
ZS 32 & 0.23 & 0.20 & 15.38 & 0.39 & 0.52 & 33.33 & 0.38 & 0.29 & 23.54 \\
ZS 35 & 0.28 & 0.29 & 7.24 & 0.45 & 0.47 & 3.97 & 0.28 & 0.22 & 19.09 \\
ZS 37 & 0.08 & 0.05 & 38.33 & 0.50 & 0.41 & 18.08 & 0.42 & 0.42 & 1.53 \\
ZS 38 & 0.12 & 0.11 & 1.53 & 0.42 & 0.47 & 10.89 & 0.46 & 0.34 & 26.94 \\
ZS 43 & 0.07 & 0.07 & 0.32 & 0.52 & 0.43 & 17.67 & 0.41 & 0.47 & 16.35 \\
ZS 45 & 0.16 & 0.19 & 23.13 & 0.73 & 0.55 & 24.71 & 0.12 & 0.16 & 32.52 \\
ZS 76 & 0.15 & 0.05 & 35.34 & 0.68 & 0.50 & 27.07 & 0.24 & 0.28 & 17.35 \\
ZS 80 & 0.23 & 0.10 & 32.63 & 0.52 & 0.59 & 14.05 & 0.33 & 0.25 & 25.60 \\
ZS 93 & 0.23 & 0.28 & 7.95 & 0.47 & 0.51 & 9.97 & 0.23 & 0.25 & 5.83 \\
ZS 100 & 0.13 & 0.24 & 5.67 & 0.42 & 0.50 & 20.06 & 0.36 & 0.31 & 12.85 \\
J8 & 0.10 & 0.26 & 25.82 & 0.46 & 0.56 & 22.86 & 0.19 & 0.16 & 13.10 \\
J11 & 0.13 & 0.12 & 9.55 & 0.62 & 0.68 & 10.11 & 0.26 & 0.29 & 15.54 \\
J12 & 0.09 & 0.10 & 13.76 & 0.61 & 0.62 & 1.38 & 0.30 & 0.36 & 19.95 \\
J13 & 0.19 & 0.15 & 21.09 & 0.55 & 0.61 & 11.90 & 0.26 & 0.22 & 16.10 \\
\hline
\end{tabular}

\section{Conclusions}

This paper presented an integrated methodology combining quantitative method for coal structure identification and prediction models of thickness proportions of coal structures.

(1) The caliper logging was first selected to recognize coal structures for high abnormal amplitudes when the coal seam suffers tectonic deformation. Higher grey correlation degree of 
0.6488 between caliper logging and coal structures proves that caliper logging can be used to evaluate coal structures.

(2) The twice modified clustering method in this work is derived from previously developed K-Means method. According to the most obvious abnormal amplitudes of log curves, the K-Means method is first modified by ascertaining initial clustering centers to avoid repeated iterative operations. The K-Means method is second modified by different grey correlation degrees between each geophysical technique and coal structures to improve accuracy. The results from twice modifications indicate that the second modification method have better validity. Therefore, coal structure can be identified fast and accurately with the aid of digital logging data.

(3) Based on the positive or negative relationships between the thickness proportions and average logging data of coal structures, the multiple linear regression method is used for thickness proportion prediction in this study. Results of three thickness proportion models suggest that this method is accurate enough with low errors for fast predicting thickness proportion of coal structures.

\section{Acknowledgements}

This research was funded by National Major Research Program for Science and Technology of China (grant nos. 2011ZX05034-001 and 2011ZX05062-006), National Natural Science Foundation of China (U1262104), the Program for New Century Excellent Talents in University (grant no. NCET-11-0721), the Foundation for the Author of National Excellent Doctoral Dissertation of PR China (201253) and the Beijing Higher Education Young Elite Teacher Project (YETP0660).

\section{References}

[1] X.H. Fu, B. Jiang, Y. Qin. "Classification of coal structures and prediction of coal reservoir permeability using geophysical logging data”, Well logging technology, vol. 27, (2003), p. 140-143.

[2] X.H. Fu, Y. Qin. "Theories and techniques of permeability prediction of multiphase medium coalbed methane reservoirs", China University of Mining \& Technology Press, (2003).

[3] X.H. Fu, Y. Qin, G.X. Wang. "Evaluation of coal structure and permeability with the aid of geophysical logging technology”, Fuel, vol. 88, (2009) , p. 2278-2285.

[4] S. Li, D.Z. Tang, H. Xu. "Advanced characterization of physical properties of coals with different coal structures by nuclear magnetic resonance and X-ray computed tomography”, Computers \& Geosciences, vol. 48 (2012), p. 220-227.

[5] G.W. Xue, H.F. Liu, W. Li. "Deformed coal types and pore characteristics in Hanchengcoalmines in Eastern Weibei coalfields", International Journal of Mining Science and Technology, vol. 22, p. 681-686 (2012).

[6] J.Q. Li, D.M. Liu, Y.B. Yao. "Evaluation of the reservoir permeability of anthracite coals by geophysical logging data", International Journal of Cola Geology, vol. 87, p.121-127 (2011).

[7] S.P. Peng, W.F. Du, C.F. Yuan. "Study on differential analysis of geophysical characteristics of coal structures and identification and prediction of combined longitudinal and transverse wave", Acta geological sinica. vol.82, p.1311- 1322 (2008).

[8] S. Yegireddi, B.G. Uday. "Identification of coal seam strata from geophysical logs of borehole using Adaptive Neuro-Fuzzy Inference System”, Journal of Applied Geophysics, vol. 67, p. 9-13 (2009).

[9] H. M. Roger. "Hydrologic properties of coal beds in the Powder River Basin, Montana I. Geophysical log analysis", Journal of Hydrology, vol. 308, p. 227-241 (2005).

[10] P. Hatherly. "Overview on the application of geophysics in coal mining", International Journal of Coal Geology, vol. 114, p. 74-84 (2013).

[11] P.L. Scholes. "Coalbed methane application of wireline logs, hydrocarbons from coal", AAPG Bulletin, vol. 38, p. 287-302 (1993).

[12] K. Frodsham, R.A. Gayer. "The impact of tectonic deformation upon coal seams in the South Wales coalfield, UK”, International Journal of Coal Geology, vol. 38, p. 297-332 (1999).

[13] Y. Chen, D.Z.Tang, H. Xu. "The distribution of coal structure in Hancheng based on well logging data", Journal of China Coal Society, vol. 38, p. 1435-1442 (2013). 
[14] J. Teng, Y.B. Yao, D.M. Liu. "Evaluation of coal textures distributions in the southern Qinshui basin, North China: Investigation by a multiple geophysical logging method", International Journal of Coal Geology, vol. 140, p. 9-22 (2015).

[15] C.Ö. Karacan. Elastic and shear moduli of coal measure rocks derived from basic well logs using fractal statistics and radial basis functions. International Journal of Rock Mechanics and Mining Sciences, 46: 1281-1295 (2009).

[16] N. Senin, M. Ziliotti, R. Groppetti. "Three dimensional surface topography segmentation through clustering", Wear, vol. 262, p. 395-410 (2007).

[17] D.G. Eberle, E.F. Daudi, E.A. Muiuane. "Crisp clustering of airborne geophysical data from the Alto Ligonha pegmatite field, northeastern Mozambique, to predict zones of increased rare earth element potential", Journal of African Earth Sciences, vol. 62, p. 26-34 (2012).

[18] Giuseppe M, Troiano A, Troise C. "K-Means clustering as tool for multivariate geophysical data analysis. An application to shallow fault zone imaging”, Journal of Applied Geophysics, vol. 101, p. 108-115 (2014).

[19] E. Sfidari, A. Kadkhodaie, S. Najjari. "Comparison of intelligent and statistical clustering approaches to predicting total organic carbon using intelligent systems", Journal of Petroleum Science and Engineering, vol. 86-87, p. 190-205 (2012).

[20] H. Zhang. "Quantitative evaluation of inversion of electrofacies using grey correlation analysis", Journal of Jiaozuo mining institute, vol. 22, p. 7-12 (1991).

[21] Y.D. Cai, D.M. Liu, Y.B. Yao. "Geological controls on prediction of coalbed methane of No. 3 coal seam in Southern Qinshui Basin, North China", International Journal of Coal Geology, vol. 88, (2011), p. 101-112.

\section{Author}

Juan Teng. He is currently a $\mathrm{Ph}$. D candidate of Mineral Resource Prospecting and Exploration in the School of Energy Resources, China University of Geosciences in Beijing, researching coal geology and coalbed methane reservoirs. His recent work has focused on laboratory investigation of coal textures of the southern Qinshui Basin in North China. 
International Journal of Hybrid Information Technology

Vol.9, No.4 (2016) 